\title{
Social Determinants of Health: Housing and Income
}

Cheryl Forchuk, Kevin Dickins and Deborah J. Corring

\begin{abstract}
Social determinants of health such as housing and income have a large impact on mental health. Community-based initiatives have worked to address access to housing, prevent homelessness and assist people who are homeless with mental health problems. There have been several large research projects to tease out multiple subgroups such as youth and veterans and other individuals experiencing longterm homelessness. The issue of poverty has been addressed by exploring issues related to employment. The use of social enterprises is a promising practice to address issues around poverty, social inclusion and employment. Similarly, the community has worked to move hospital-based employment programs to the community.
\end{abstract}

\section{Social Determinants of Health}

The term social determinants of health refers to those "economic and social conditions that shape the health of individuals, communities and jurisdictions as a whole" (Raphael 2009: 2). Raphael gives examples of economic and social conditions as gender, education, income and its distribution in society, housing, employment and job security, access to food, access to healthcare, living with a chronic disability and membership in a minority racial group. These aspects, alone or in combination, have been shown to have a stronger association with ill health than the effects of an individual's behaviour related to diet, smoking, physical activity or alcohol consumption (Raphael 2009).
The determinants of health were integral to the drawing up of the Ottawa Charter for Health Promotion in 1986 and were also considered central to achieving "Health for All" by the year 2000 and beyond. The concept of health promotion includes people's capacity to actively participate in control of their health with the proviso that certain prerequisites need to be met. These provisos link back to the social determinants of health and include peace, shelter, education, food, income, a stable ecosystem, sustainable resources, social justice and equity (World Health Organization [WHO] 1986). In regard to the promotion and maintenance of mental health, these determinants are particularly significant.

Within the London-Middlesex area, we have had a number of projects examining two specific social determinants housing/homelessness and income/poverty. There have been two Community and University Research Alliance (CURA) initiatives over the past decade to enhance capacity building in these areas using a participatory action research (PAR) approach through the active engagement of community agencies, people with lived experience and researchers.

\section{Housing}

From 2002 to 2006, the Social Sciences and Humanities Research Council (SSHRC) funded a five-year CURA project on housing and mental health. This programmatic funding enabled the development of research capacity within multiple community agencies and further understanding of how these complex 
issues occur in the context of a mid-sized city surrounded by small towns and rural communities. One priority was to better understand the reason for homelessness increasing as a mental health issue and to develop strategies to address this trend. The impact of deinstitutionalization of psychiatric survivors from long-stay hospitals to community-based mental healthcare, along with changing housing policy (from the federal to provincial and then municipal levels), placed some individuals at increased risk of homelessness throughout Ontario and Canada. The deinstitutionalization process happened during a period when affordable housing was limited, particularly the public housing stock. Despite the dramatic decrease of available beds within psychiatric hospitals during the early 1990s, a concurrent increase in community-based housing did not occur. The disconnect between housing policy, income support policy, and mental health policy at the provincial level in this period resulted in a situation where many people with mental health problems found themselves homeless (Forchuk et al. 2007). For example, the Toronto shelter system found that approximately two-thirds of its population had a previously diagnosed addiction and an additional two-thirds were diagnosed with other psychiatric conditions (Goering et al. 2002). In London, specific diagnoses are not tracked at the shelter level.

The provision of stable housing and having a place to call home is a basic human need (WHO 1986). A number of strategies have been developed and implemented in London that address such concerns as preventing discharge from psychiatric hospital wards to homelessness (Forchuk, Vann et al. 2011; Forchuk, Godin et al. 2013a and 2013b), addressing the specific needs of homeless youth (Forchuk, Richardson et al. 2013) and homeless veterans (Forchuk et al. in press).

To prevent discharge to homelessness, a baseline study was conducted to determine the extent of this issue. Using data from London shelters and hospitals, this phenomenon occurred, conservatively, almost 200 times per year (Forchuk et al. 2006). An intervention was then developed to more quickly provide in-hospital access to housing stability income support through a partnership with the local offices of Ontario Works and Ontario Disability Support Program, as well as providing available housing support through the local Canadian Mental Health Association (CMHA). This intervention, after pilot testing (Forchuk et al. 2008), was further refined with online support from the wards, including access to the Ontario Works database, as well as a database of accessible housing in the London area. Following this intervention, the shelter data showed a $90 \%$ drop, from an original 200 cases to just 15 direct discharges to their emergency services (Forchuk et al. 2013b; Forchuk, Richardson et al. 2013).

Another example of a collaborative project is London Community Addiction Response Strategy (CAReS), a non-profit organization that aims to improve the health and housing outcomes of individuals experiencing homelessness who live with the complex and co-occurring challenges associated with addiction, mental health and poverty. A recent study explored outcomes in health and housing, as well as participants' healthcare utilization and emergency shelter use before and after enrollment in London CAReS. The study identified reductions in emergency room visits, resulting in decreased strain on the healthcare system while supporting individuals in the community (Forchuk et al. in press).

The work of the CURA on mental health and housing/ homelessness was cumulated into a 2011 book (Forchuk, Csiernik et al. 2011) that contains two dozen chapters of published works emerging from collaborative efforts.

\section{Income/Poverty}

The London community was unprecedented in receiving a second CURA from SSHRC. The second CURA initiative focuses on poverty and social inclusion among psychiatric survivors.

The relationship between poverty and mental illness is both straightforward and complex (CMHA 2007). People with mental illness often live in chronic poverty, and conversely, poverty is a significant risk factor for poor physical and mental health (CMHA 2007). Understanding this broader context is key to addressing poverty, through the promotion of mental health and in supporting the recovery of persons with mental illness. Having a stable income, either from employment or through financial support and benefits, is directly related to other determinants of health, namely affordable housing and rent, food and transportation to access healthcare (Raphael 2009). Social inclusion, or the ability to engage fully in the community, is also somewhat dependent on available finances (Mikkonen andRaphael 2010). A community-based solution is the development of social enterprises to provide competitive quality employment for people who have experienced a mental illness. Our CURA on poverty and social inclusion has partnered with community agencies to evaluate these new approaches to employment. Examples include IMPACT Junk Solutions (IMPACT), as well as a variety of employment strategies, to replace the previously closed hospital-based employment programs at St. Joseph's Health Care London's Regional Mental Health Care Program in London and St. Thomas.

\section{Transitioning Employment Programs From Hospital to Community}

Vocationally related activities have been a part of the care for patients in St. Joseph's mental health programs throughout its history. Over the years, vocational activities have included farm work, work placements within the hospital departments and programs, greenhouse work, and light industrial packaging and assembly. As the field of vocational rehabilitation progressed, greater emphasis was placed on preparation for employ- 
ment, such as upgrading education and work opportunities outside of these institutions. Sheltered workshops at both sites preceded supported employment. Sheltered workshops provide revenue-generating alternatives to the general labour market for individuals with disabilities, including psychiatric disabilities, while supported employment programs equip individuals with necessary supports and services to be successful in competitive employment (Canadian Association for Community Living 2011). Feedback from participants of the sheltered workshop programs over the years has been positive. They reported the importance of being productive, being accepted, not feeling pressured, and having opportunities for socialization. Unfortunately, a move from this type of sheltered "employment" to competitive employment was achieved by only a few.

The 1997 directives from the Health Services Restructuring Commission (HSRC) of Ontario resulted in a number of changes to the delivery of mental healthcare services in southwestern Ontario. The governance and management of the two psychiatric hospitals was transferred to St. Joseph's Health Care London in 2001, during the initial phase. Subsequent phases in 2011 resulted in the transfer of beds and related services to four other communities, leading to a shift of resources to the community, the closure of the two vocational programs attached to the hospitals and the construction of two new mental healthcare facilities. Functional planning for the two new facilities did not involve continuing the two vocational programs. In keeping with provincial mental health reform philosophy, vocational and other rehabilitation services were to be provided in the community, rather than at an institution, in order to better assist individuals with mental illness in their reintegration into everyday life (Ontario Ministry of Health and Long-Term Care 2011).

The two programs were situated on the grounds of each hospital site and were committed to providing client-centred vocational services. The primary focus was to assist individuals to develop employment skills and provide vocational training and education opportunities. The predominant work that was available consisted of light assembly and packaging from local industry. Individuals could work a few hours or several hours per week, depending on their wish to work and their work tolerance. The limitations of what they could earn placed on them by the Ontario Disability Support Benefits and/or by other disability pension also impacted the number of hours worked, as did the availability of work available to individuals.

Clients accessing these services had a wide range of abilities and potential for competitive employment. When the closure of the two sheltered employment programs was announced, service users expressed a significant sense of loss and anxiety regarding their future. Reassurances were provided with alternative work spaces in the community, but these were met with a fair degree of pessimism.
Preparation for the closure of these services with transition to more evidence-informed vocational rehabilitation services, such as supported and transitional employment, began in earnest when partnerships across sectors were formed with the local South West (SW) LHIN: Goodwill Industries, CMHA Elgin, and the previous Western Ontario Therapeutic Community Hostel (WOTCH) organization, which later became part of CMHA London-Middlesex. In order to track what happened to individuals after these services closed and to assess the impact on them, a formal evaluation was planned and the CURA Vocational Transitions project became part of a larger CURA social enterprise initiative.

The St. Thomas sheltered workshop program closed its doors in June 2013. Goodwill developed new services in St. Thomas, based on a light industrial contract platform. Goodwill Pivotal was launched in July 2013, with some initial one-time funding from the SW LHIN. It was premised on the "choose, get and keep" model of psychiatric rehabilitation, established in the last few decades by researchers at Boston University (Danley et al. 1992). Goodwill Pivotal provides a social enterprise environment with a focus on productivity and assistance for individuals who face barriers to competitive employment. An additional service element was added that focused on transitional employment with wraparound supports, including job coaching, job-seeking support and a job development specialist. CMHA Elgin received annual funding from the SW LHIN and developed services designed to provide vocational preparation and experiences for individuals.

With London closing its sheltered workshop in March 2014, Goodwill expanded its London operation to accommodate persons who were interested in pursuing employment with them, and similar to St. Thomas, added a transitional employment element to its overall services. CMHA London-Middlesex welcomed referrals to its individualized (particularly, placement and support) vocational services, which were primarily based on a place-then-support model, for those interested in the opportunities they provided. The CURA Vocational Transitions research project has tracked individuals affected by these closures and is nearing the end of the evaluation period, with results to be reported in 2016 .

\section{IMPACT Junk Solutions}

Designed to be an innovative solution to the high unemployment rate amongst individuals diagnosed with a mental illness, IMPACT was launched in the spring of 2012 as a selfsustaining social enterprise of CMHA London-Middlesex. IMPACT provides professional junk removal and commercial cleaning services to the London area. As a revenue-generating enterprise that does not receive any direct funding from CMHA or any other government source, this model poses significant operational challenges. However, these challenges 
are outweighed by the benefits created through the development of a competitive employment opportunity, rather than being yet another funded program.

Having started with only 3 employees, IMPACT has quickly grown to accommodate over 25 staff in its brief 3-year existence. With each employee living with a mental health diagnosis, the perception from the community, at times, is that the quality of work will be inferior to that of a traditional provider. Contrary to these perceptions, IMPACT has been the recipient of multiple awards and nominations and has received recognition as the Ontario Government's first ever Social Enterprise Strategy. The employees of IMPACT were privileged in both 2013 and 2015 with the London Free Press Best of London award for the best junk removal/recycler. This recognition signified the community's embracing of the social enterprise and the abilities of those working within it.

Honoured by the Social Enterprise Strategy of Ontario, IMPACT has established a unique business model, not only for a social enterprise but unique for any revenue-generating company. IMPACT operates its junk removal service with a triple bottom line philosophy that ensures social, environmental and financial sustainability; "Focusing on People, Planet, and Profit" allows IMPACT to be successful while creating new working and learning opportunities for employees.

When IMPACT employees remove items from a customer's home or property at a cost, they transport the items back to their warehouse. They then carefully sort items that can and will be kept in the warehouse and those that can be recycled, either by another social enterprise or through other recycling avenues, as is done with electronics and metals. The items that are kept in the warehouse are instrumental to creating an ecosystem of community building. Furniture and household items are repurposed by donation to individuals and families in need, often three to four times a week. This act of social beneficence allows the employees of IMPACT to be in the position of service providers, not service recipients, a responsibility they cherish and excel in.

To date, IMPACT has diverted over 52 tons of material from landfills, either through its recycling efforts or by donations. This environmental stewardship has resonated with customers, who now call upon IMPACT as opposed to other competitors, knowing that their items can be repurposed.

In addition to junk removal services, IMPACT operates a residential and commercial cleaning service that makes up roughly $70 \%$ of its workforce. The cleaning contracts provide steady, routine employment for the cleaning employees. The cleaning contracts take place in the evening, a schedule that employees find works well with their living habits and sleep patterns. The cleaning staff fulfill several responsibilities beyond cleaning the contracted properties; they also ensure that buildings are locked each evening and alarm systems are activated upon the completion of their shifts. Their relationships with customers have been instrumental in combatting the stigma associated with mental illness.

IMPACT has benefitted from having a workforce comprised entirely of individuals with lived experience, as none of their previous concerns with staff turnover, absenteeism and human resources management have been realized. The dedication and commitment to work demonstrated by the employees of IMPACT illustrate the advantage that competitive employment has on the well-being and recovery of individuals living with a

\section{Lessons Learned}

- It is believed that the transition of vocational support services from an institution base to that of a community agency such as was undertaken by St. Joseph's is relatively unique in the group of former provincial psychiatric hospitals.

- Although discussions began several months before the first closure, it took considerable time to put alternatives in place as they had to be built from the ground up. Although time was spent with individuals to plan for the change, the resulting down time for clients proved difficult for them. Over time, many have resumed participation in one of the alternatives but some have not done so.

- It became apparent that some of the clients were unable to make the transition due to a lack of ability to transition from a sheltered environment to one that was supportive but more demanding than the institution-based program they had been involved with in the past. If other organizations were to consider such an initiative, a planning period of at least one year is recommended to ensure smooth transitions for clients.

- The promise provided by social enterprises is worth further exploring in mental health. While there are many examples of successful social enterprises, they tend to be grassroots organizations and communityspecific. Developing a social enterprise often requires different skill sets than those typically needed within organizations that provide mental healthcare. It requires an entrepreneurial approach, marketing and a strong business case to be developed.

- Linking with and learning from other social enterprises is an important strategy for success. The Social Enterprise Council of Canada can be a useful resource. However, there does not appear to be any specific list of social enterprises specifically addressing the needs of people with mental illnesses. 
mental health diagnosis. Growth of this social enterprise and the awards and recognition it has already received speak to the gains made in reducing the stigma surrounding mental illness. The employees of IMPACT continue to develop themselves while strengthening their communities, one junk removal call at a time.

\section{Implications/Conclusion}

In order to address the social determinants of health, particularly as they are manifested in people with mental illness and addiction issues, it is important to foster partnerships that cross all sectors of social care and healthcare. Those who advocate for this specific subpopulation of society must think beyond solutions that predominantly focus on the mental health sector. In London, there has been a great deal of work to not only address social determinants of health, but also to evaluate the effectiveness of such approaches. $\mathrm{HQ}$

\section{References}

Canadian Association for Community Living. 2011. Achieving Social and Economic Inclusion: From Segregation to "Employment First." Toronto, ON: Canadian Association for Community Living.

Canadian Mental Health Association, Ontario. 2007. Poverty and Mental Illness. Retrieved November 11, 2015. <http://ontario.cmha. ca/public_policy/poverty-and-mental-illness/\#.VbjR0bXwDhk.>

Danley, K.S., K. Sciarappa, and K. MacDonald-Wilson. 1992. "Choose-Get-Keep: A Psychiatric Rehabilitation Approach to Supported Employment." New Directions for Mental Health Services 53, 87-96.

Forchuk, C., R. Csiernik and E. Jensen. 2011. Homelessness, Housing, and Mental Health: Finding Truths, Creating Change. Toronto, ON: Canadian Scholars' Press Inc.

Forchuk, C., M. Godin, J.S. Hoch, S. Kingston-MacClure, M.S. Jeng, L. Puddy and E. Jensen. 2013a. "Preventing Homelessness After Discharge From Psychiatric Wards: Perspectives of Consumers and Staff." Journal of Psychosocial Nursing and Mental Health Services 51(3): 24-31.

Forchuk, C., M. Godin, J.S. Hoch, S. Kingston-MacClure, M.S. Jeng, L. Puddyand E. Jensen. 2013b. "Preventing Psychiatric Discharge to Homelessness." Canadian Journal of Community Mental Health 32(3): $17-28$.

Forchuk, C., L. Joplin, R. Schofield, R. Csiernik, C. Gorlick, and K. Turner. 2007. "Housing, Income Support and Mental Health: Points of Disconnection." Health Research Policy and Systems 5: 14.

Forchuk, C., S.K. MacClure, M. Van Beers, C. Smith, R. Csiernik, J. Hoch and E. Jensen. 2008. "Developing and Testing an Intervention to Prevent Homelessness Among Individuals Discharged From Psychiatric Wards to Shelters and 'No Fixed Address.'” Journal of Psychiatric and Mental Health Nursing 15(7): 569-75.

Forchuk, C., J. Richardson, and H. Atyeo. In press. "Addressing Homelessness Among Canadian Veterans." In Canadian Observatory on Homelessness, eds., Exploring Effective Systems Responses to Homelessness. Toronto, ON: The Homeless Hub.
Forchuk, C., J. Richardson, K. Laverty, M. Byrant, A. Rudnick, R. Csiernik, ... and C. Kelly. 2013. "Service Preferences of Homeless Youth With Mental Illness: Housing First, Treatment First, or Both Together." In S. Gaetz, B.O'Grady, K. Buccieri, J. Karabanow and A. Marsolais eds., Youth Homelessness in Canada: Implications for Policy and Practice. 95-110. Toronto, ON: Canadian Homelessness Research Network Press.

Forchuk, C., G. Russell, S. Kingston-MacClure, K. Turner and S. Dill. 2006. From Psychiatric Ward to the Streets and Shelters. Journal of Psychiatric and Mental Health Nursing 13(3): 301-08.

Forchuk, C., R. Vann, E. Wilura, J. Hoch, M. Jeng, S. KingstonMacClure and E. Jensen. 2011. "Reducing Psychiatric Discharges to Homelessness.” European Psychiatry 26(1): 1717.

Goering, P., G. Tolomiczenko, T. Sheldon, K. Boydell and D. Wasylenki. 2002. "Characteristics of Persons Who Are Homeless for the First Time." Psychiatric Services, 53(11): 1472-74.

Mikkonen, J. and D. Raphael. 2010. Social Determinants of Health: The Canadian Facts. Toronto, ON: York University School of Health Policy and Management.

Ontario Ministry of Health and Long-Term Care. 2011. Open Minds, Healthy Minds: Ontario's Comprehensive Mental Health and Addictions Strategy. Ontario: Queen's Printer for Ontario.

Raphael, D. 2009. Social Determinants of Health: Canadian Perspectives (2nd ed.). Toronto, ON: Canadian Scholars' Press Inc.

World Health Organization. 1986. The Ottawa Charter for Health Promotion. Retrieved from http://www.who.int/healthpromotion/ conferences/previous/ottawa/en/WHO.

\section{About the Authors}

Cheryl Forchuk, RN, PhD, is a distinguished university professor in nursing and psychiatry at Western University and assistant director at Lawson Health Research Institute, the research arm of the London hospitals. Dr. Forchuk can be reached by email at: cforchuk@uwo.ca.

Kevin Dickins is the manager of community programs at CMHA Middlesex in London, Ontario, and served as the lead for the launch of Impact Junk Solutions.

Deborah J. Corring, PhD, is the owner/operator of the consulting firm Client Perspectives and recently retired as the project lead for Mental Health Transformation, St. Joseph's Health Care London. 